\title{
Connexivity and the Pragmatics of Conditionals
}

\section{Andreas Kapsner ${ }^{1}$}

Received: 15 August 2019 / Accepted: 8 September 2020 / Published online: 24 November 2020 () The Author(s) 2020

\begin{abstract}
In this paper, I investigate whether the intuitions that make connexive logics seem plausible might lie in pragmatic phenomena, rather than the semantics of conditional statements. I conclude that pragmatics indeed underwrites these intuitions, at least for indicative statements. Whether this has any effect on logic choice (and what that effect might be), however, heavily depends on one's semantic theory of conditionals and on how one chooses to logically treat pragmatic failures.
\end{abstract}

\section{Introduction}

Connexive logic, as a research programme in philosophical logic, is motivated by powerful intuitions about the clear defectiveness of statements like

If $A$ is the case, then not- $A$ is the case.

I strongly believe that these intuitions must be accounted for in some way or other, even though they have been largely ignored, at least until recently. Those who have not ignored them have usually been trying to develop a semantic account of conditionals and negations that leads to a connexive logic, a move that requires considerable logical revision. In this paper, I will investigate whether this could maybe not be necessary, because the intuitions might be explained by pragmatic phenomena instead; in particular, I will be looking at the pragmatics of conditionals to answer this question.

The question breaks up into two more specific ones that will lead us through the essay:

Q-Pragmatic: Are there pragmatic principles that help explain our strong intuitions about statements like "If $A$ is the case, then not- $A$ is the case"?

Q-Revision: Is this pragmatic explanation all there is to it, and will it thus lead to less drastic logical revision than what the connexive logicians call for, or maybe none at all?

Andreas Kapsner

Andreas.Kapsner@1rz.uni-muenchen.de

1 Munich Center for Mathematical Philosophy, Ludwig-Maximilians-University,

Geschwister-Scholl-Platz 1, 80539 Munich, Germany 
The outline of the paper is as follows: In a first part, I will introduce the principles of connexive logic and supply a first analysis of the intuitions that lie behind their plausibility. I will show that the intuitions are equally strong for indicative and counterfactual conditionals. The second part will discuss the pragmatic features of conditionals that might help explain those intuitions and present my answer to Q- PRAGMATIC: I will argue that such an explanation works for indicative conditionals, but not for counterfactuals. Lastly, a third part surveys the upshots for logic choice of such an explanation and thus supplies my answer to Q- REVISION, this time a resounding "It depends".

Two remarks about what to expect: First, from a logical point of view the paper is quite programmatic in nature, in that it discusses rather general features of semantic and logical theories rather than particular systems. My aim is to get the goal into clearer focus, how to get there is beyond the scope of this piece. As a result, the material is not heavy on formal technicalities; in fact, I hope that even philosophers of language and linguists who are not particularly interested in logic at all might be able to get something of value, especially out of the part on pragmatics.

Second, although I am sympathetic to the aims of the lately invigorated and growing connexive community, I try to conduct this investigation without any foregone conclusions in mind (however, I will allow myself some opinionated comments at the very end of the essay). I will present a range of options, and though I find some of these more plausible than others, I believe they can all be incorporated into a generally feasible theory of conditionals which will, in particular, all have some success in accommodating the connexive intuitions. Some of them will require adopting a connexive logic, others will not. What is common to all of them is that they can make a claim to do justice to the intuitions motivating connexivity, and that they entail changes to commonly held assumptions about logic, semantics and/or pragmatics.

\section{Part I: Connexive Logic and Connexive Intuitions}

\section{Connexive Logic: Principles and Variations}

Connexive $\operatorname{logics}^{1}$ are non-classical logics that are characterized by the following principles:

Aristotle: $\neg(A \rightarrow \neg A)$ and $\neg(\neg A \rightarrow A)$ are valid.

Boethius: $(A \rightarrow B) \rightarrow \neg(A \rightarrow \neg B)$ and $(A \rightarrow \neg B) \rightarrow \neg(A \rightarrow B)$ are valid. $^{2}$

\footnotetext{
1 The best place to start an exploration into the topic is Wansing (2020) and the references therein. Alternatively, McCall (2012) is a useful starting point. A third good resource is Wansing et al. (2016). Regarding the latter, one of the reviewers has asked me to comment on the relation between the ideas in the present paper and the notion of an "empty promise conversion", a term Wansing, Omori and Ferguson take from an earlier work of mine (Kapsner 2014) and apply to the realm of connexivity. I agree that there is a certain facetious nature that empty promise conversions and pragmatically faulty assertions (can) share. However, I must admit that I am still not quite done thinking through the ramifications of applying the idea of empty promise conversions in the new context of connexive logics itself. I hope to come to more useful conclusions about this in the future.

${ }^{2}$ From now on, I will skip the negation permutations of these clauses and write only, e.g., $\neg(A \rightarrow \neg A)$, meaning $\neg(\neg A \rightarrow A)$ to be silently implied as well.
} 
These principles surely seem plausible when the connectives are read with their usual meaning, and it is the aim of this paper to get clear about where that feeling of plausibility comes from. Before we get there, though, let me say a little bit more about the peculiar status of connexive logics in the landscape of present day philosophical logic. Let me also take the opportunity to sketch my personal view on how to think about connexivity, as it will be helpful to know the perspective from which this paper is written.

The connexive principles, ${ }^{3}$ although that surprises many students even after a thorough introductory course in logic, are not valid in classical logic. That is what makes connexive logic a topic in non-classical logic, but the pattern is interestingly different from that of other non-classical logics. In all other well-known cases, the non-classical logic rejects something that is valid in classical logic, such as the Law of Excluded Middle, Explosion or some other classical principle. ${ }^{4}$

Connexive logics, in contrast, ask for more validities than classical logic gives us. It so happens that this is impossible without giving up other things in turn: Classical logic is Post-complete, which means that adding new axioms without removing others will trivialize the resulting logical system. Accordingly, much of the philosophical work in the field of connexive logics takes the form of a cost-benefit analysis, weighing the attractiveness of ARISTOTLE and BOETHIUS against the undeniable discomfort of giving up other principles one might like to keep. I will not go into the specifics of this balancing act here; instead, my aim in this part is to describe and assess the weight and the nature of what is on one of the sides of the scale: the intuitive attractiveness of the connexive principles.

As I have noted, the principles strike most people as common-sensical when they look at them and translate them into natural language statements. ${ }^{5}$ Now, it is important to note that this is true whether we read the arrow as an indicative conditional or whether we read it as a subjunctive or counterfactual ${ }^{6}$ one:

It is not the case that if I go to France next year I do not go to France next year.

It is not the case that if I were to go to France next year, I would not go to France next year.

Also, changing tense is not making much of a difference:

It is not the case that if I went to France last year I did not go to France last year.

It is not the case that if I had gone to France last year, I would not have gone to France last year.

\footnotetext{
3 A reviewer reminds me to also mention the negative condition that the conditional should not be symmetric, i.e. that we should not be able to infer $A \rightarrow B$ from $B \rightarrow A$. This might seem like an observation too obvious to make, but it happens that many seemingly promising routes to connexivity lead to a rather sad place in which the conditional has turned into a biconditional.

4 See, for example, Priest (2008) for a wide-angled overview.

5 I have collected anecdotal evidence for this from many sources, Pfeifer (2012) reports getting similar results with a much cleaner methodology.

6 I will come back to the uneasy line between subjunctives and counterfactuals in Sect. 5.1.
} 
All of these, I would suggest, seem equally true. Indeed, they seem trivially true. Instances of BOETHIUS, though still more unwieldy and unlikely to come up in conversation, seem upon reflection equally true. I will only give one example explicitly, the adjustment to achieve the three variations that are analogous to the examples above are obvious:

If it is the case that I will have a good time if I go to France next year, then it is not the case that I will not have a good time if I go to France next year.

Strong as they might be, I think that the intuitions about such statements are derivative in their nature, that is, that they are based on more fundamental ones. I take it that the intuition that leads to thinking that $\neg(A \rightarrow \neg A)$ is valid is actually grounded in an intuition about $A \rightarrow \neg A$. Here is a first rough suggestion as to what that intuition might be (it will get more precise in the next section): There is something seriously wrong with asserting natural language instances of $A \rightarrow \neg A$. For BOETHIUS, I believe that the intuitive core of finding $(A \rightarrow B) \rightarrow \neg(A \rightarrow \neg B)$ and its twin $(A \rightarrow \neg B) \rightarrow \neg(A \rightarrow B)$ plausible is the following intuition: There is something seriously wrong with someone's saying both $A \rightarrow B$ and $A \rightarrow \neg B$. If you say one, you should not say the other. ${ }^{7}$

This line of thought has led me to point out (Kapsner 2012) that connexivists should ask, in addition to ARISTOTLE and BOETHIUS, for the following unsatisfiabilityconditions:

UnSat1: In no model, $A \rightarrow \neg A$ is satisfiable. ${ }^{8}$

UnSat2: In no model $A \rightarrow B$ and $A \rightarrow \neg B$ are satisfiable simultaneously (for any $A$ and $B$ ).

Logics that satisfy these two clauses in addition to ARISTOTLE and BOETHIUS are called strongly connexive logics, while those that only satisfy ARISTOTLE and BOETHIUS are called weakly connexive logics.

It may be surprising to learn that logics that are only weakly connexive even exist, but they do: Many attractive connexive logics are ruled out if one insists on UNSAT1 and UNSAT2. In fact, at least in view of the current theoretical landscape, it might even appear that strong connexivity will turn out to be too high a bar to clear, at least for any logic that is suitable for natural language analysis.

In view of this difficulty, I have more recently made a suggestion how we might lower the bar slightly without giving up my demand for the unsatisfiability-conditions. This suggestion is based on the observation that there is one area in which the compelling nature of our intuitions might start to fade. This concerns impossible or contradictory antecedents:

\footnotetext{
7 There are two alternatives to the formalization of BOETHIUS that might bring out this intuition even more clearly, namely what Pizzi and Williamson call WeAK BoEthius, $(A \rightarrow B) \supset \neg(A \rightarrow \neg B)$ (Pizzi and Williamson 1997), and the thesis known as ABELARD or STRAWSON's THESIS, $\neg((A \rightarrow B) \wedge(A \rightarrow \neg B))$. I thank one of the reviewers for urging me to mention these, though I have felt that a detailed discussion of which is the correct or best way of expressing the underlying intuition would have made this piece intolerably long.

8 I here reproduce what I had written then. A commentator of this piece tells me that "... is satisfied" instead of "... is satisfiable" would have been clearer to him.
} 
It is not the case that if $A$ and not- $A$ are both the case, then it is not the case that

$A$ and not- $A$ are the case.

Assuming someone is able to parse things like that correctly, maybe they won't feel as strongly pushed towards accepting this as true as in the other cases discussed above. This puts in doubt whether the formalized version of the above, $\neg((A \wedge \neg A) \rightarrow$ $\neg(A \wedge \neg A))$, should come out logically valid.

In my paper Humble Connexivity, ${ }^{9}$ I have argued that the connexive principles should be restricted so as not to apply to such cases. A logic achieves humble connexivity if ARISTOTLE, BoETHIUS, UnSAT1 and UnSAT2 hold in all cases that do not involve impossible antecedents. The details are somewhat more intricate than one might expect. Instead of going into this much further here, let us agree to simply disregard such statements for the purposes of this paper. ${ }^{10}$

I will only note the following: In proposing the humble restrictions, my intention was not to say that achieving a more ambitious form of connexivity that does not make such restrictions would be philosophically bad per se. It's just that we know that a logic will explode if we push it to do too much work; the impossible antecedents are, in my view, a valve that we can easily open up to let off some steam. But the pressure is still considerable. Even if we don't ask for ARISTOTLE, BOETHIUS and the UNSAT-clauses to hold in cases involving contradictions, but only when the constituent statements are garden variety contingent statements, we are still asking for a considerable revision of classical logic. In classical logic, ARISTOTLE will fail in each case in which $A$ is simply false, no matter whether $A$ is contradictory or consistent. Indeed, most other non-classical logics are in a similar situation. ${ }^{11}$ Even though humble connexivity has lowered the bar, it is still quite high.

Pondering this problem has led me to the questions I investigate in this paper, in particular the ones I have called Q- PRAGMATIC and Q- REVISION above. My aim in this piece is to uncover the ultimate source of the connexive intuitions: I am interested in whether they stem from the semantics of conditionals and negation, or whether they are intuitions about pragmatics (Q- PRAGMATIC). If the latter is the case, maybe we don't need to revise logic at all, or only in a less radical way than we thought (Q- REVISION). I will unpack these possibilities in the later sections of this piece; for now, we will have to start by getting clearer about what the connexive intuitions are, exactly. ${ }^{12}$

\footnotetext{
9 Kapsner (2019). I have since learned that the essence of my idea has been around for many centuries. It goes back to Leibniz (see Lenzen 2019), further back to the twelfth century philosophers Afzal ad-Din Kashani in the east (see El-Rouayheb 2009) and Alberic of Paris in the west (see Estrada-González and Ramírez-Cámara 2020), and maybe, if we follow Wolfgang Lenzen's speculation, back to Aristotle himself (see Lenzen 2020). Much more recently, Andrea Iacona has suggested a similar idea and coupled it with a defense of strict implication, see Iacona (2019), and also the manuscript Crupi and Iacona (2019).

10 Let us also agree to bracket dialetheism (the view that some contradictions are true) and the closely related idea of truth value gluts (statements that are, in some sense, both true and false).

11 Interestingly, some of the exceptions to this are to be found in the realm of conditional logics (see Kapsner 2019), a topic we'll touch on again below.

12 N.B.: Until the last part of this investigation, I will have no reason to untangle ARISTOTLE, BOETHIUS, UNSAT1 and UNSAT2, as well as their humbly restricted versions. I will until then refer to them as "the connexive principles" and understand them in the way I have outlined in this section, i.e., the way I proposed in Kapsner (2019). However, those who think I was wrong in asking for the UnSat-principles or in settling for the humble versions can keep their own preferred understanding in mind without much danger of confusion.
} 


\section{Connexive Intuitions, in More Detail}

Again, I claim that the core of the connexive intuitions is the thought that there is something very wrong with asserting things like $A \rightarrow \neg A$ etc. If we want to make that rather fuzzy characterization more precise, there are several ways to do this. I present three that I take to be promising (leaving out variations in tense, such as "If $A$ was the case, then not- $A$ was the case"). They are increasing in strength, at least under commonly held ideas about assertion conditions, truth values and negation. ${ }^{13}$

\section{A: Unassertability}

ARISTOTLE: It can never be right to say something like

"If $A$ is the case, then not-A is the case"

and neither can it be right to say something like

"If A were the case, then not-A would be the case".

BOETHIUS:

"If $A$ is the case, then $B$ is the case" and "If $A$ is the case, then not- $B$ is the case"

can never be correctly assertable together, and neither can

"If A would be the case, then B would be the case" and "If A would be the case, then not-B would be the case".

Here, all we are taking the intuitions to come down to is that instances of $A \rightarrow$ $\neg A$ etc. cannot be asserted correctly in any conversational circumstance. The word "together" in the explication of the intuitions behind BOETHIUS is imprecise: It could mean "at the same time in the same conversation" or "at the same time in the same conversation by the same speaker"; I mean the latter, but the former is of course another way to spell out our intuitions that one might want to consider. In any case, whether the unassertability has to do with the semantic value of these statements or not is left open. The next version is more specific on this:

\footnotetext{
13 A note on negation: In general, I believe that many of the interesting features of connexive logic concern the interplay between conditionals and negations. However, in this piece I am not focusing on negations, as the points about pragmatics I make do not depend on the particulars of any account of negation, at least until Sect. 9. Until then, I require little of negation beyond this: $A$ and $\neg A$ can never be true together, cf. footnote 10
} 


\section{B: Untruth}

ARISTOTLE: The statement

"If $A$ is the case, then not-A is the case"

can never be true, and neither can

"If A were the case, then not-A would be the case".

\section{BOETHIUS:}

"If $A$ is the case, then $B$ is the case" and "If $A$ is the case, then not- $B$ is the case"

can never be true at the same time, and neither can

"If A would be the case, then B would be the case" and "If A would be the case, then not-B would be the case".

Here, the unassertability of the statements has to do with semantic values; however, it is still left open by these clauses what exactly it has to do with them: It could be the case that the statements always take a value that is associated with unassertability (i.e. falsity on most accounts, or possibly some other undesignated value in many-valued settings). However, it could also be the case that they simply fail to take a semantic value at all. The last version is explicit on this question:

\section{C: Falsity}

ARISTOTLE: The statement

"If A is the case, then not- $A$ is the case"

is always false, and so is

"If A were the case, then not-A would be the case".

\section{BoETHIUS: One of}

"If $A$ is the case, then $B$ is the case" and "If $A$ is the case, then not-B is the case"

must be false, and so must be one of

"If A would be the case, then B would be the case" and "If A would be the case, then not-B would be the case".

In this last version, it is clear that we are dealing with semantic values as the main source of connexive intuitions: $A \rightarrow \neg A$ and its variations take the truth value "false", as does at least one of $A \rightarrow B$ and $A \rightarrow \neg B$. 
It might be worthwhile to try to find out empirically whether one of these formulations captures people's intuitions more clearly than the others, but I have some doubts that untrained subjects will be perfectly clear about which of them is the most plausible. I will get back to this point towards the end of the paper, but let me here nonetheless speculate a bit: I believe that most people will agree at least to the plausibility of UNASSERTABILITY, and that a large majority would go on to UNTRUTH. Whether they would go on to FALSITY will depend, I suspect, on the presentation of the options. If only FALSITY is on offer to either accept or reject, I suspect they will embrace FALSITY, but if they can choose between all three options, they might stop at UNTRUTH. It is between UNTRUTH and FALSITY that my own intuitions waver, though one might argue that my intuitions on this question are compromised by now.

In any case, I will keep all three options on the table as I move into the next part of this paper, in which I will launch my investigation into the main questions of this piece: Whether these intuitions ${ }^{14}$ could be explained by an appeal to pragmatic principles (Q- PRAGMATIC), and, if so, whether we might not need to ask for logic to validate the connexive principles (Q- REVISION). A positive answer to both questions would leave the non-connexive logician in a very comfortable place: She would not have to dispute the connexive intuitions, but the issue could be handed to the linguists and philosophers of language who analyze matters of pragmatics.

To see whether such hopes are well founded or in vain (or if it is something in between, in that the appeal to pragmatics leads to a milder logical revision than expected), let us start to look into which kinds of pragmatic constraints are at play here, and whether any of them explain our connexive intuitions.

\section{Part II: The Pragmatics of Connexivity}

\section{Saving Logic from Intuitions: Grice}

The project of explaining connexive intuitions by appeals to pragmatics takes on a roughly similar form as Gricean explanations ${ }^{15}$ of seeming counterexamples against the material conditional analysis of indicative conditionals.

Grice held that to say $A \rightarrow B$ in a situation where one knows of the truth of either $\neg A$ or $B$ (or both) will be pragmatically incorrect, even if what one is saying is true. It is incorrect because it violates several conversational maxims.

According to the material analysis Grice defends, what one is saying is equivalent to $\neg A \vee B$, and using the disjunction or something that is equivalent to a disjunction implies that the speaker knows nothing more specific than that at least one of the disjuncts is true. It is, thus, misleading to utter the statement instead of simply asserting the disjunct which one knows to be true. The latter would also be more concise and more informative.

Maybe one could try to defend the truth of at least some instances of $A \rightarrow \neg A$ (namely those instances in which $A$ is false), while explaining the connexive intuitions

\footnotetext{
14 Until I get to drawing the fine-grained distinctions between UNASSERTABILITY, UNTRUTH and FALSITY, I will use the term "connexive intuitions" to vaguely cover all of them.

15 See Grice (1989).
} 
that go against such statements by using these considerations. We would be lead to conclude that the true core of our intuitions is UNASSERTABILITY, and that UNTRUTH would already be going too far, not to speak of FALSITY.

Here is what such a possible line of defense would look like that aims to show why ARISTOTLE seems so compelling and why $A \rightarrow \neg A$ seems so wrong: $A \rightarrow \neg A$ just means $\neg A \vee \neg A$, and it would be more concise and more elegant to just say $\neg A$.

However, unlike in the more general case, note that it is not really more informative to say $\neg A$ instead of $\neg A \vee \neg A$. It is also not really misleading to say the latter. The speaker who says something with this logical form is not pretending to know less than she does; she is only using clumsy language to say what she knows. For a conditional which is asserted on grounds of knowing the precise truth value of the antecedent, the consequent, or indeed both, and which is judged defective on Gricean grounds, this would seem to be one of the least offensive cases possible. ${ }^{16}$

But that diagnosis of inoffensiveness does not ring true to me. Take a case that should feel parallel, but (at least to me), does not: $A \wedge A .{ }^{17}$ That, translated to natural language, is just a very strange and complicated way to say $A$. The strangeness can be made explicit by appeal to Gricean maxims, and that lets us see why the statement would normally not be correctly assertable. But at no point in thinking about this example would anyone have thought it couldn't be true. I feel no inclination to respond "Now that can't be true, can it?" to $A \wedge A$, while I do in the case of $A \rightarrow \neg A$. In my terminology above, my intuition is to go further than UNASSERTABILITY here, but the Gricean strategy cannot take us further along. ${ }^{18}$

Though conversational maxims won't get us beyond UNASSERTABILITY, there are pragmatic stories that lead to UNTRUTH, and maybe even to FALSITY. However, instead of general conversational maxims, we need to start to look at the specific pragmatic principles that attach to indicative and counterfactual conditionals for that purpose.

\section{The Pragmatics of Conditionals}

There is no clear consensus on the pragmatics of indicative and subjunctive conditionals. In the upcoming sub-sections, I will go through some important views on this, but here I will immediately start out with what strikes me as the correct account. ${ }^{19}$

\footnotetext{
16 What about the intuitions behind BoEthIUs, i.e. the incorrectness of asserting $A \rightarrow B$ and $A \rightarrow \neg B$ at the same time? According to classical logic, one is asserting both $\neg A \vee B$ and $\neg A \vee \neg B$. This is only possible to do correctly in a situation in which one knows that $\neg A$ is true, and thus it would be more concise and less confusing to just say that. Again, it wouldn't necessarily be misleading, as a little thinking should lead the hearers to the conclusion that it can only be on the grounds of $\neg A$ that these assertions could be made. I think the case is roughly parallel, but the intuitions I allude to in the next paragraph are stronger and clearer for $A \rightarrow \neg A$.

17 Or think of $(A \rightarrow A) \wedge A$ in case you think a comparison not involving a conditional is unfair.

18 Andrea Iacona, in commenting on a draft, adds a nice thought to what I have said here: "If $A$, then not- $A$ " and "If not- $A$, then $A$ " feel like sharing the same kind of defect, but the Gricean will have to give a very non-symmetric analysis: One case will be pragmatically defective, while the other will simply be false (in corresponding order if $A$ is false, in reverse order if $A$ is true).

19 In case you are more interested in connexivity than the intricacies of the pragmatics of conditionals, you might want to cut this section short in the following way: Check whether what I say in the next paragraphs
} 
I take the central pieces of the pragmatics of conditionals to be two presuppositions, one attaching to indicatives, one to counterfactuals. ${ }^{20}$ Presuppositions of a statement are, roughly, things that need to be true in order for the whole statement to even have a chance of being true.

Here is the form these presuppositions take:

\section{Presuppositions of Conditionals}

Indicative Presupposition (IP): Indicative conditionals presuppose that the antecedent is epistemically possible for the speaker.

Counterfactual Presupposition (CP): Counterfactuals presuppose that the antecedent is false.

To see how plausible these principles are, think of someone saying on Monday

If today is Tuesday, then it's Mary's birthday.

IP claims that this could be a non-defective assertion only if the speaker actually doesn't know that today is Monday. ${ }^{21}$ If he signals in some way that he does know, then he has clearly made some mistake or is trying to communicate something vastly non-literal. For example,

If today is Tuesday, then it's Mary's birthday. Today is Monday.

just sounds plainly wrong, assuming the speaker utters these sentences without any pause in which she might acquire new information about which day it is. Here, the presupposition IP is not met, and that is the source of the trouble with that statement. The most charitable reading of this might be to suppose that the speaker is not a native speaker of English and meant to use the subjunctive mood to utter a counterfactual, in which case the pair of assertions would be fine:

If today were Tuesday, then it would be Mary's birthday. Today is Monday.

Not only is there no problem with the speaker knowing the antecedent to be false, this is actually called for by $\mathbf{C P}$, the presupposition I have suggested to hold for counterfactuals. This presupposition does little more than to ask for a counterfactual to be counter to fact, something that sounds close to analytically true. That there is, nonetheless, some contention around this principle will be discussed in the next subsection.

Footnote 19 continued

below is plausible and only skim the rest of the section from Sect. 5.1 onwards; come back later, if needed. Though this is a feasible way to read the paper, I think it is necessary to argue for my account in as much detail as I do in this section because it is, to my knowledge, not to be found in the literature, and some of the accounts that have been proposed do not work as an explanation of connexivity.

20 An important idea about the pragmatics of counterfactuals that has nothing to do with presuppositions is put forward in Moss (2012). It has, however, no import on the questions I am concerned with here, so I leave it to one side.

21 I use " $A$ is epistemically possible for the speaker" in what I take to be the standard way, that is, to mean "For all the speaker knows, $A$ might turn out to be true". 
Do these presuppositions help account for the connexive intuitions beyond what we have seen so far? On the face of it, the Gricean strategy laid out above would explain the unassertability of the example sentence in the indicative mood in a way that might not seem too different from IP: According to Grice, what the speaker has said is equivalent to

Either today is not Tuesday, or it's Mary's birthday.

Uttered on the grounds that today is Monday, this is needlessly complex and misleading.

IP differs from the Gricean strategy in two important ways: First, it makes no presumption about the correctness of the material conditional analysis of indicative conditionals. Moreover, the Gricean analysis rests on an idea about the assertability of disjunctions that is not needed for the more direct IP. Second, in regarding IP a presuppositon, one is making a committment to honoring intuitions that the first sentence in

If today is Tuesday, then it's Mary's birthday. Today is Monday.

is not just saying something misleading, but indeed something that is not true. A presupposition that can not be satisfied, as I said above, precludes the truth of the statement. $^{22}$ Whether that means that the statement is false is a separate question that I will return to below. At this point, just note that the explanation of the connexive intuitions that utilizes IP is more general than the Gricean strategy (in not being committed to the material analysis of conditionals), and that it helps account for the stronger versions of these intuitions, be they UNTRUTH or FALSITY.

The two presuppositions I propose are somewhat asymmetric, in that IP makes reference to the epistemic state of the speaker, while $\mathbf{C P}$ does not. That is not to say that the epistemic state of the speaker is irrelevant to CP: not only must she use a statement that is false as the antecedent of a counterfactual, she must also believe that the antecedent is false in order to make a correct assertion. But the latter is implied by her realizing that the antecedent needs to be false to justify her use of a counterfactual (realizing that is part of using this device correctly). On the other hand, to use a counterfactual correctly, it is not enough to just believe the antecedent to be false, it must actually be false. To say

If you hadn't lied to me back then, we would still be friends.

is objectionable if the addressee didn't lie, even if the speaker believes him to have lied.

I have not seen the above pair of IP and $\mathbf{C P}$ proposed together in the literature so far, but I don't want to claim that they are very original. ${ }^{23}$ The ideas, or slight variations

\footnotetext{
22 The only exception of this view I know is Bergmann's (1981), who allows for true statements with false presuppositions. However, the cases she has in mind are exemplified by statements like "Either the king of France is bald or $2+2=4$." She takes this statement to retain the presupposition that there is a king of France, while the more usual view has it that this statement has no presupposition. This is mostly a verbal dispute about what "presupposition" means which has no further bearing on my topic here.

23 While I think that these are correct presuppositions to posit, I am not sure that they are the only ones. For example, it strikes me as plausible to add that "If $A$ is the case, then $B$ is the case" presupposes that
} 
of them, were expressed by others before, just not in this exact combination. The suggestions I found that were closest to mine are by Brian Leahy, by Lauri Karttunen and Stanley Peters, and by Robert Stalnaker. Let me comment on our differences before I explain how an account of the connexive intuitions might (or might not) be able to make use of these presuppositions.

\subsection{Leahy}

Leahy (Leahy 2011) endorses IP, and thus we are in complete agreement on indicatives. However, he does not endorse $\mathbf{C P}$; rather, he believes that counterfactuals have no presuppositions at all. ${ }^{24}$ I think that most of our difference lies in the oft-lamented terminological situation at this point: As counterfactuals are, at least in English, expressed by switching to the subjunctive mood, "counterfactual conditionals" and "subjunctive conditionals" are often used synonymously. This leads to some subjunctive conditionals that are used as counterexamples to principles such as the presupposition I suggested above. The poster-child that is cited by virtually everyone who claims that counterfactuals might have true antecedents is the following example by Alan Anderson:

If he had taken arsenic, he would have shown exactly the symptoms that he in fact showed. So he likely took arsenic (Anderson 1951).

It is slightly ironic that Anderson himself did not use "counterfactual conditionals" and "subjunctive conditionals" as synonymous. Furthermore, he meant his example to show that not all subjunctive conditionals need to have false antecedents, while he did not dispute that counterfactuals do.

Quite similarly, where researchers like Leahy see counterexamples to the presupposition I suggest, I see conditionals in the subjunctive mood in the English language that happen not to express counterfactuals. I am, again, not claiming originality for this view, as it goes back to at least Anderson. It is also quite in harmony with what Stalnaker says about subjunctives and counterfactuals in Stalnaker (1975a), a paper I will discuss in more detail below. What bearing the difference in opinion between Leahy and me has on the topic of connexivity will be answered in Sect. 6.2.

\subsection{Karttunen and Peters}

Karttunen and Peters (Karttunen and Peters 1979), on the other hand, come close to agreeing with both IP and CP.

Karttunen and Peters fall into the same camp as Leahy when it gets to identifying subjunctive and counterfactual conditionals and thereby allowing counterfactuals that

Footnote 23 continued

not- $A$ is also an epistemic possibility for the speaker. This addition would make no real difference to the argument in this essay, though.

24 Incidentally, Leahy notes that he, like me, also does not think that his proposal is really new. He suggests that it might be equivalent to Karttunen and Peters' as well as to Stalnaker's. I think that it will become clear in what follows that these three proposals are all distinct. 
have true antecedents. This leads them, however, to a weaker version of $\mathbf{C P}$, as opposed to the claim that subjunctives/counterfactuals have no pragmatic restrictions at all on them, as Leahy argues.

They write (Karttunen and Peters 1979, p. 8):

"If $A$ then $B$ " conventionally implicates:

a. Indicative mood

"It is epistemically possible that $A$ "

b. Subjunctive mood

"It is epistemically possible that not- $A$ "

Again, I will discuss the import of that difference compared to CP in 6.2. For now, there are two more things to draw your attention to:

First, they don't make it clear for whom the antecedent's truth or falsity must be epistemically possible. IP makes it clear that it is the speaker whose epistemic state is at issue, while we will see a different view in the next section. As I don't know which camp to sort Karttunen and Peters into, I will say nothing more about it in this section.

The second interesting difference between their proposed restrictions and IP and CP is that the latter are framed as presuppositions, while Karttunen and Peters take them to be conventional implicatures.

Now, the line between presuppositions and conventional implicatures is hardly a clear one. Precise usage varies among authors, who often don't give a direct comparison between their reading of the two notions. Where the distinction is drawn explicitly, it looks to be a rather thin line. In one of the clearest discussions I know, Christopher Potts (Potts 2015) claims that the main difference between the two is that presuppositions are "backgrounded" (p. 174), while conventional implicatures are not. That means that presuppositions need to be present in the common ground ${ }^{25}$ between the participants of a conversation before the utterance, while conventional implicatures must be new to the common ground.

However, there are mechanisms that neutralize this difference:

- For presuppositions that are new, there is the familiar notion of accommodation, going back to Lewis (1979). If an utterance requires a certain presupposition that is not yet part of the common ground, then the hearers normally quietly add it to the common ground.

- For conventional implicatures that are not new to the conversation, Potts employs the idea of "evoked content" (Potts 2015, p. 190). The idea is that by using a sentence that conventionally implicates some fact that is already part of the common ground, that fact can thereby be brought back to attention, or its importance can be underlined.

Given those possibilities, it is unclear how the distinction between presuppositions and conventional implicatures can be neatly drawn in practice. Indeed, Potts goes on to suggest that the future of pragmatics might lie in the merging of categories such as these two, rather than more fine-grained frameworks (Potts 2015, p. 192).

\footnotetext{
$\overline{25}$ I will say more about the notion of a common ground in the next section. Roughly, it is what everyone in the conversation assumes to be the case.
} 
However, there $i$ s an important difference between presuppositions and conventional implicatures, after all: As I mentioned above, a failed presupposition is usually taken to preclude the truth of the statement, while a false conventional implicature has no influence on the truth or falsity of the statement. ${ }^{26}$

This difference will be important when I get to discuss the logical upshots of my investigation of pragmatics in Sects. 8 and 9, and I will further develop the topic there.

\title{
5.3 Stalnaker
}

In this last subsection, I want to look at a proposal that is due to Robert Stalnaker, who first developed it in his Stalnaker (1975a). It has been quite influential and, again, shares much with IP and CP; the differences between these principles and those he suggests, however, carry more weight than was the case in the other proposals discussed so far, and it will be worthwhile to pay close attention to them.

Stalnaker's full theory of the semantics and pragmatics of conditionals is rich and has inspired much subsequent research; it is also quite subtle, and it has changed over the years. Looking back, he moreover once described his own writing as "vague and equivocal" (Stalnaker 2002, p. 701), and regarding at least some of the specifics, it is not implausible to agree with him on this. I will not attempt a full reconstruction of his theory here; I will only do so much as to bring out our differences and commonalities concerning the presuppositions in sufficient detail.

For Stalnaker, the pragmatics of indicative and counterfactual conditionals play a most important role. He thinks that semantically, there is actually no difference between the two kinds of conditionals. ${ }^{27}$ It is only in their presuppositions that they differ.

To express these presuppositions, he makes use of a notion that I have already mentioned above without explaining it further, namely that of a common ground of a conversation. The common ground is what the participants of the conversation collectively take for granted. ${ }^{28}$ That they in fact do take something for granted collectively might have different reasons. The standard case (meaning the most common and most straightforward case) is that they believe it, believe that the others believe it as well, believe that the others believe that everyone in the conversation believes it, etc.; that

\footnotetext{
${ }^{26}$ Laurence Horn puts the latter thought succinctly:
}

\begin{abstract}
For Grice (...), a conventional implicature $\mathrm{C}$ associated with an expression $\mathrm{E}$ manifests the following two definitional properties: (i) by virtue of being conventional, $\mathrm{C}$ constitutes a non-cancelable aspect of the meaning of E, and (ii) by virtue of being an implicature, C's truth or falsity has no affect (sic) on the truth conditions of E. (Horn 2007, p. 39)
\end{abstract}

See also Potts (2005), p. 49 on the matter.

27 The semantics he proposes is much better known as a semantic theory for counterfactuals than for indicatives. I assume a general acquaintance with it in some of what follows; here is a thumbnail sketch to remind the reader: A conditional "If $A$, then $B$ " is true in our actual world if $B$ is true at the closest $A$-world. That is, the most similar (in a sense of similar that is not completely straightforward to spell out) world to the actual world in which $A$ is true.

28 See Stalnaker (2002) for the fullest discussion of this notion by Stalnaker himself. When talking in terms of formal semantics, Stalnaker uses the notion of a context set to model the common ground; I will stay at the unformalized level and keep talking about the common ground. 
is, the standard is for common grounds to be constituted by common belief. Something is commonly believed either because it has been asserted and accepted in the earlier course of the conversation, because it is obvious common background knowledge, or because it is a salient feature of the context in which the discussion takes place.

Note that a common ground that is constituted by what is commonly believed might well hold open the possibility of the truth of a statement that the speaker actually thinks is false. ${ }^{29}$ That is, not- $A$ might not be in the common ground, even though the speaker believes $A$ to be false. The converse, of course, holds: whatever actually is in the common ground needs to be believed by the speaker, at least in the standard case in which common belief and the common ground coincide.

However, this does not hold in other, non-standard cases that Stalnaker repeatedly draws our attention to: In these cases, Stalnaker allows that what is in the common ground actually need not be believed by the conversants. There are special contexts in which it is enough to be ready to assume (or to accept, or to take for granted) that everything in the common ground is true, if only for the sake of the conversation at hand.

In Stalnaker (2002), ${ }^{30}$ he writes:

One may simplify or idealize in an inquiry, one may presume innocence to ensure fairness, one may make assumptions for the purpose of contingency planning, one may grant something for the purpose of an argument.

These kinds of contexts are indeed important and interesting. I believe that what I say below about the standard cases carries over to the non-standard cases, namely that $\mathbf{I P}^{31}$ and $\mathbf{C P}$ are preferable to Stalnaker's proposal. However, I found a satisfying discussion of the matter to be a quite complicated affair, with many cases to consider and intuitions in some of them turning rather murky. I have therefore decided to leave this discussion for another time and concentrate on the standard case.

Let me, then, present Stalnaker's proposal for the presuppositions of conditionals, which are expressed in the theoretical framework that I have just sketched out.

Here is what Stalnaker takes the presuppositions of indicatives and counterfactuals to be:

\section{Stalnaker's Presuppositions of Conditionals}

Stalnaker's Indicative Presupposition: Indicative conditionals presuppose that nothing in the common ground rules out the truth of the antecedent.

Stalnaker's Counterfactual Presupposition: Counterfactuals presuppose that the truth of the antecedent is ruled out in the common ground.

\footnotetext{
29 Or even of a statement which everyone individually in the conversation thinks of as false, but where this fact has not yet become common knowledge.

30 See also Stalnaker (1975a), p. 273.

31 Or better, a version of IP that talks about acceptance instead of belief.
} 
The first of these is clearly stated in the text of Stalnaker (1975a), ${ }^{32}$ the second not quite so clearly. At times he simply writes that counterfactuals presuppose the falsity of the antecedent, ${ }^{33}$ just as I did in proposing CP. However, his general theory of presupposition (cf. Stalnaker 1975b) ensures that the two ways of expressing the condition come to the same thing, and expressing the presupposition as I did ensures that that general part of his theory is also captured.

Even without the specifics of Stalnaker's theory of presuppositions in the background, it will turn out that the difference between the two ways of expressing the condition, and thus the difference (if there is any) between his proposal for counterfactuals and CP is not important, at least for the questions I am focused on in this piece.

The case of the indicative conditional, on the other hand, is quite another issue: We saw above that it makes quite a difference whether you say that a proposition must be a possibility left open by the common ground, or whether you say that it must be an epistemic possibility for the speaker. Moreover, this is a difference that will turn out to be important.

To decide which account is more promising, take again the example I introduced above:

If today is Tuesday, then it's Mary's birthday. Today is Monday.

Even though this seems clearly unassertable, Stalnaker cannot explain why this must be the case. It could well be that the common ground leaves the question open which day it is, because it is not common belief that today is Tuesday (maybe the two statements were preceded by someone else asking "What day is today?"). In that case, Stalnaker's presupposition is met, while IP is not met.

Similarily, to say, in a conversation where nothing is commonly known about the beverage-related habits of the speaker,

If I have some beer in the fridge, you can have one. I don't, though, I never have beer in the fridge.

is not just a lame move, it also seems linguistically defective to me. But, again, Stalnaker's presupposition does not predict a defect; IP does. ${ }^{34}$

Note that in well-behaved contexts, there can be no cases where the pattern of the last two examples is reversed, i.e., where Stalnaker would predict a presupposition failure and IP would not. If the common ground between you and me is constituted by our common belief, then it cannot preclude something that I think is possible. It

\footnotetext{
32 Albeit often expressed in terms of the context set instead of the common ground. Moreover, Stalnaker does not posit this presupposition on its own, but rather infers it from a condition on his formal semantics that says, roughly, that indicative conditionals are to be evaluated at worlds in the context set.

33 See p. 274 and p. 279 of Stalnaker (1975a).

34 One of the reviewer has criticized this example on the following grounds:

"Generally, it is assumed in pragmatics (with Grice) that the speaker and the listener cooperate to make the speaker-listener interaction successful. However, the authors describe a case in which the speaker seems to deceive the listener. It is thus unsurprising that pragmatic accounts might not work in such cases."

It is not clear to me that the bad intentions of the speaker make the pragmatical principles inapplicable. Quite to the contrary, to my mind, the virtue of IP is that it explains why the statement is deceptive.
} 
can not be common belief between you and me that $A$ is not the case while I believe that $A$ might be true.

So, IP implies Stalnaker's presupposition: If the speaker holds that the antecedent is a live possibility, then there can be nothing in the common ground that precludes it, as we are assuming that she believes everything in the common ground.

In making the last observation, I used the qualification "in well-behaved contexts" because this implication breaks down when the common ground is defective. This is Stalnaker's term to describe situations in which there are divergent beliefs between the members of a conversation about what the common ground actually is. In such cases, it may well be that I hold something to be epistemically possible, while you think that our common ground rules it out.

In defective contexts, it might seem that Stalnaker's presupposition is adding an important element that IP doesn't cover.

For example, it seems at the very best borderline acceptable for an underage girl to tell her unsuspecting parents

If I'm pregnant, I'll call the baby Kim, no matter whether it's a girl or a boy.

if a possible pregnancy was not part of the common ground before.

Still, the ensuing discussion will probably not center on questions of linguistic appropriateness. More to the point, at least linguistically the example seems much less problematic than the example involving Mary's birthday; and as far as it does have linguistic problems, I would argue that they have little to do with the conditional per se. You might have realized that the example is riffing on an example of von Fintel's that Stalnaker mentions in Stalnaker (2011). In the example a daughter informs her father that she is getting married by saying

O Dad, I forgot to tell you that my fiancé and I are moving to Seattle next week.

The problem in these two examples is the same one: The daughter forces the parents to fix their end of the defective common ground via accommodation, where the importance of this information would call for a much more direct act of communication. If the topic were a less exciting one, or if it was not your daughter but one of your colleagues at work telling you these things, there would be little wrong with either of the examples.

In general, I submit that cases involving defective common grounds can be handled by IP at least as well as by Stalnaker's presupposition, and I can't think of any other examples in which IP might run into problems while Stalnaker's presupposition would not (these would have to take the form of a pragmatically acceptable statement that is ruled out by IP but not by Stalnaker's presupposition, given that the latter is implied by the former). Therefore, I conclude that in the standard case, where common ground and common belief come to the same thing, IP is preferable to Stalnaker's presuppostion. 


\section{Connexive Intuitions, Pragmatically Explained}

Armed with a proposal for the pragmatics of conditionals, as well as an understanding of some of its alternatives, let us now come to the first core question of this essay (QPRAGMATIC): Can we explain the connexive intuitions by appealing to these pragmatic features? For those who are, by now, at least somewhat excited about this possibility, there is good news and bad news ahead. I will start with the good news, which concerns the indicative flavor of conditionals.

\subsection{Indicative Conditionals: Success (at Least with the Right Presupposition)}

Starting with ARISTOTLE, here is how IP might explain the intuition that "If $A$ is the case, then not- $A$ is the case" is never assertable.

According to IP, if a speaker asserts $A \rightarrow \neg A$, then she is presupposing that $A$ is epistemically possible for her.

But the speaker undercuts that presupposition immediately with the consequent of the conditional. While that seems pre-theoretically obvious to me, ${ }^{35}$ an explanation of how that undercutting exactly works will depend on the details of the semantic story we choose to give for indicative conditionals. ${ }^{36}$ If this story fails to give such an explanation, then this would, in my opinion, speak strongly against it.

Here are four examples of how semantic theories of conditionals help explain why the presupposition ${ }^{37}$ fails:

Material Conditional In the simplest case, where some version of the material analysis is defended, the speaker who asserts $A \rightarrow \neg A$ says nothing more nor less than $\neg A$. That is, she is denying the possibility of that which, according to the presupposition, should be epistemically possible for her.

Constructive/Intuitionistic Conditional For those favoring a constructive or intuitionistic interpretation of indicative conditionals, asserting $A \rightarrow \neg A$ means something like this: If you give the speaker a construction that proves that $A$, he can turn that into a construction that proves $\neg A$, which is a definitional abbreviation of $A \rightarrow \perp$. Combining the two, the speaker can give you a construction that proves $\perp$. Such a construction is impossible, so that means that he is certain that you will not be able to provide a construction of $A$ (he has made what I have elsewhere called an "empty promise conversion", see footnote 1). But that means

\footnotetext{
35 Indeed, this insight is so obvious that I see no problem in judging speakers to be not fully competent if they do not understand this. Thus, someone who asserts $A \rightarrow \neg A$ but does not understand that this somehow (she of course needn't be able to explain exactly how) rules out the possibility of $A$ is not making a correct assertion, because she does not understand a key part of the meaning of what she is uttering. I take it that such understanding is required for a correct assertion.

36 Of course, to a certain extent it also depends on our account of negation. For example, if $A$ and $\neg A$ can be true together, there is not much undercutting going on. That is why, earlier on, I based my considerations in this piece on the rather minimal (but not uncontested) assumption about negation that $A$ and $\neg A$ can never be true together.

37 Or the conventional implicature, if we want to accept Karttunen and Peters's version. As I said above, that move would allow the asserted statement to be true. But that does not mean that what is implicated itself might be true in this case.
} 
that the truth (or provability) of $A$ is not an epistemic possibility for him, which goes against the presupposition.

If you think that intuitionistic logic provides the right formalization of the informal constructive interpretation, a quicker argument is that $A \rightarrow \neg A$ is, as in classical logic, equivalent to $\neg A$.

Strict Conditional Here we are thinking in terms of possible worlds: $A \rightarrow \neg A$ means that in all the accessible worlds from the actual one, if $A$ is the case, then $\neg A$ is the case at that world. There are only two cases in which this is possible: If there are no accessible worlds from the actual one (including itself), or if $A$ is true in none of the accessible worlds. Regarding the first possibility, I have not seen any proposal to analyze indicatives in terms of a strict conditional in which the actual world might be a "dead-end" world. Regarding the second, usually the modality underlying the strict analyses is some kind of wide-ranging possibility, either logical or metaphysical. That is, the only cases in which $A$ will be true at no accessible world will be those in which $A$ is impossible. By virtue of the logical form of her statement, the speaker makes a committment to the impossibility of $A$, and thus violates the presupposition. ${ }^{38}$

Variably Strict Conditional For a reason very similar to the last one, a view of conditionals along the lines of Stalnaker's Stalnaker (1975a) would tell us that anyone who makes a statement with the logical form $A \rightarrow \neg A$ is ruling out the possibility of the antecedent. Again, his proposal was to use the same semantic account (plus some pragmatics) he gave for counterfactuals. The account is sometimes called a "variably strict" theory of conditionals, making the close connection to the strict account explicit. The "variable" part makes no difference: The only case in which $A \rightarrow \neg A$ could be true is the one in which $A$ is impossible.

In more general terms, if your conditional entails the material conditional (as is the case for most of the common variations of the last two items, but not the case for, e.g., intuitionistic logic), then the consideration about the material conditional above is all you need to think through. ${ }^{39}$

Now, let us look at how the intuitions behind BOETHIUS might be explained by IP. Why can't it be correct to say both "If $A$ is the case, then $B$ is the case" and "If $A$ is the case, then not- $B$ is the case"? Because, according to IP, $A$ should be epistemically possible for the speaker, and this possibility is not on the table any more if both conditionals are true. Again, the specifics of why it is off the table depends on the semantic account of the conditionals. For example, in the material case, one is saying "Either not- $A$ or $B$ " and "Either not- $A$ or not- $B$ ". In one of these, the second disjunct can't be true. Thus, the first disjunct, not- $A$, must be true for the disjunction to be true. And if not- $A$ is true, the possibility of $A$ 's truth is not open any more. Explanations

\footnotetext{
$\overline{38}$ To avoid a possible misunderstanding, note what this explanation is meant to achieve: It would be a way for a defender of the strict conditional view to explain what is behind the pre-theoretic intuition that $A \rightarrow \neg A$ rules out the truth of $A$, based on the logical form of the statement. It is not trying to say that, on the strict conditional view, in order to have that pre-theoretic intuition, one would have to realize the impossibility of $A$ on its own. Of course, there are statements that are logically or metaphysically impossible, while they might well be complex enough to be an open epistemic possibility for a speaker.

39 Thanks to Andrea Iacona for urging me to make this clear.
} 
given in terms of the other semantic accounts of conditionals would proceed in a way that is similarly parallel to the explanations of the unassertability of $A \rightarrow \neg A$ above.

To sum up: It appears that IP can supply a convincing pragmatic explanation of the connexive intuitions. Let us now look at Stalnaker's proposal for the presuppositions of indicatives and see if a similar explanation could be had here. Again, Stalnaker's presupposition only requires that, in a statement like $A \rightarrow \neg A$, the antecedent should be an open possibility in the common ground of the conversation.

There might be accounts of the semantics of indicatives that brew up some trouble in this case, but I am not aware of any. To give just one example, consider the material analysis of someone saying $A \rightarrow \neg A$ while Stalnaker's presupposition is met. On the material view of conditionals, this is equivalent to saying simply $\neg A$ in a conversation in which, up to that point, there was nothing in the common ground that precluded $A$. There is obviously no problem with that.

In general, I believe that there is no way that Stalnaker's indicative presupposition can lead to a pragmatic explanation of the connexive intuitions. I have made my case for IP and against Stalnaker's proposal. Those who are not convinced and still favor the latter over the former will have to give up hope for a pragmatic explanation of the connexive intuitions about indicative conditionals. Those who accept IP, in contrast, can avail themselves of such an explanation. What they can do with such an explanation will be explored after we take a look at counterfactuals.

\subsection{Counterfactual Conditionals: No Pragmatic Explanation in Sight}

As for counterfactuals, the hopes of explaining the connexive intuitions by appeal to pragmatics are rather dim on any of the proposals I have discussed. We have seen that there are three options on the table: Either they have no specific pragmatic principles associated with them at all, or they presuppose the falsity of the antecedent, or they presuppose ${ }^{40}$ that the falsity of the antecedent is at least epistemically possible (either for the speaker or for all participants of the conversation). In the first case, it is obvious that there is nothing to be had here, so we are left with the second and the third (that is, $\mathbf{C P}$ and Karttunen and Peters's proposal, respectively).

As I pointed out above (see Sect. 5), if $\mathbf{C P}$ is correct, then the speaker must also believe that the antecedent is false in order to speak correctly. A fortiori, she must believe that the antecedent is possibly false. Thus, Karttunen and Peters's presupposition is entailed by $\mathbf{C P}$. I think that even the stronger $\mathbf{C P}$ can't yield an explanation of the connexive intuitions, so that this remains the only case to be examined.

Let us, then, begin with an attempt to explain the intuitions behind ARISTOTLE with the help of CP: If I say

If $A$ had been the case, then not- $A$ would have been the case

and $\mathbf{C P}$ is correct, then what I say presupposes that $A$ is false at the actual world. The consequent does not seem to contradict this. In fact, on a very naive way of thinking about this, it might even seem that this is exactly what it states. But of course, it is commonly accepted that the consequent of a counterfactual should not be evaluated

40 Or rather, as we take this last idea from Karttunen and Peters, they conventionally imply this. 
at the actual world (or the actual situation, or in the obtaining state of affairs, or in reality, or whatever fits your semantic setup most comfortably). The presupposition, on the other hand, is about the actual world. There is neither corroboration nor tension between what is presupposed and what is said here.

To understand why the statement above is unassertable, one needs to understand something about the semantics of the statement. According to some of our best theories, what one needs to understand is that $A$ must be true in the world (or worlds, or situation(s), or state(s) of affairs ... ) in which the statement is to be evaluated, and to understand that in such a world, not- $A$ can therefore not be true, and thus, that the whole statement must be false. But all of that is a matter of semantics, not pragmatics.

As for the intuitions behind BOETHIUS, to understand why saying both

If $A$ had been the case, then $B$ would have been the case

and

If $A$ had been the case, then not- $B$ would have been the case

at the same time is wrong, $\mathbf{C P}$ is no help. Instead, one needs to understand (again, if one of the family of our most successful theories in the field is correct) that both statements need to be evaluated at a world (state of affairs...) in which $A$ is the case, and that in such a world, $B$ and not- $B$ can't both be true, and that thus the two statements cannot be asserted together. And again, this is a matter of semantics, not pragmatics.

In sum, what is doing the explanatary work for indicatives is that the antecedent has to be epistemically possible for the speaker. This is not a presupposition that attaches to counterfactuals, and the ones that do (if any) cannot step up to do the job.

Thus, it seems to me that $\mathbf{C P}$, and therefore also the weaker alternatives we have explored, cannot add to an explanation of the connexive intuitions. If we want to do right by them, then we will have to deal with that in our semantic theory. As I mentioned above, we are in luck here, as at least some of the favorite theories for counterfactuals conform to the connexive theses, provided we take them in their humble form (see Sect. 2). ${ }^{41}$

To sum up what has been claimed in this part:

- There is a presupposition for indicatives (which I called IP) that says that the antecedent needs to be epistemically possible for the speaker: If I say "If today is Monday, Susy will come home tomorrow", then this is only correct if I don't know for sure that today is not Monday.

\footnotetext{
41 See Kapsner (2019), where I show that Stalnaker's, but not Lewis's theory of counterfactuals achieves humble connexivity. That there is strong conceptual affinity between connexive logics and conditional logics has long been recognized, see McCall (2012). Latley, the intersection of these topics has seen some interesting further developments, see Weiss (2019), Wansing and Unterhuber (2019) and Kapsner and Omori (2017).
} 
- This presupposition rules out the correct assertibility of statements like "If today is Monday, today is not Monday".

- However, this presupposition does not hold for counterfactuals: If I say "If I hadn't met my wife, my children would not have been born", then that surely does not presuppose that my not meeting my wife is epistemically possible for me.

- Therefore, an explication running parallel to the indicative case does not work, nor will explanations building on other presuppositions for counterfactuals.

In terms of our guiding pair of questions, this leaves us with an answer of the first and a restriction of the second:

Q-Pragmatic: Are there pragmatic principles that can help explain our connexive intuitions?

Answer: Yes, in the case of indicative conditonals. No, in the case of counterfactuals.

Q-Revision: In the case of indicatives: Is this pragmatic explanation all there is to it, and will it thus lead to less drastic logical revision than what the connexive logicians call for, or maybe none at all?

Answer: Read on.

\section{Part III: Logical Upshots}

So far, we have learned that the pragmatics of conditionals judge that assertions like $A \rightarrow \neg A$ are incorrect for indicatives, but not for counterfactuals. What does that mean for logic choice? After all, we are interested in what we can learn about connexive logic from all this.

The answer to that question depends on two very general issues. First: What general shape is our theory of conditionals supposed to take? And second: How are we going to treat presupposition failures (or false conventional implicatures) logically?

I will spend the next two sections to talk about these questions one by one.

\section{V-and Y-shaped Accounts of Conditionals}

So, let us start with the first question: What shape is, ultimately, our theory of conditionals going to take?

The talk of shapes is of course not quite literal, but it almost is. Jonathan Bennett has introduced a very vivid way of talking about two general shapes such theories can take. He calls them "Y- shaped" and "V-shaped" theories (see Fig. 1). 


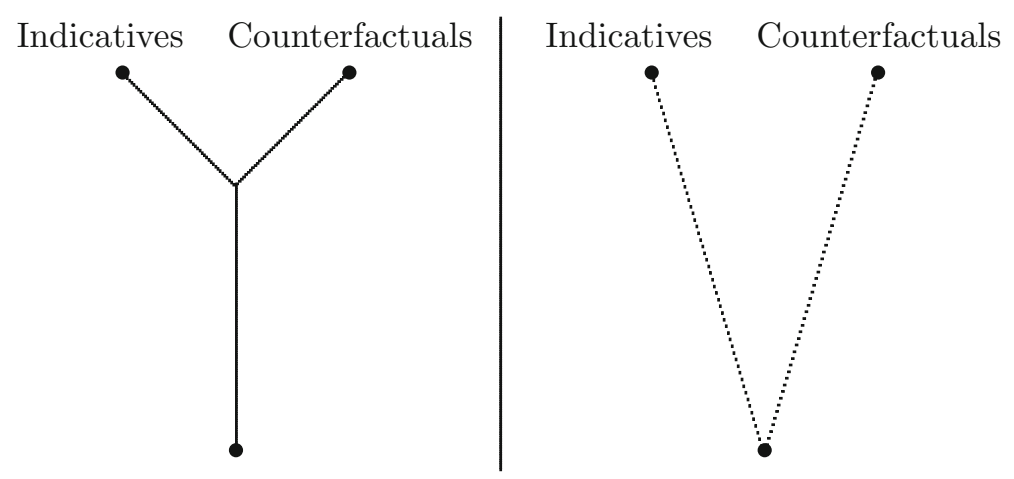

Fig. 1 Different kinds of theories of conditionals (Bennett 2003)

A Y-shaped theory (what others sometimes call a "unified" theory) tries to give an account of the semantics of indicatives and counterfactuals that is as closely related as possible. The account shares all of the stem of the Y-shape, and only bifurcates at the last possible moment. One classic example of this is Stalnaker's own theory, ${ }^{42}$ who holds that the pragmatic constraints on indicatives are the only difference between indicatives and counterfactuals. That is, the whole account involving variable strictness, the idea of most similar worlds, etc. is located on the stem of the Y, and the only additional idea on one of the branches (the indicative branch) is that the pragmatic constraint is in place.

The main attraction of a Y-shaped theory is that it explains why indicatives and counterfactuals are sharing so much in terms of surface grammar (see Stalnaker 1987, p. $111 \mathrm{ff}$, for this and other arguments, and Bennett 2003 for discussion).

In contrast, those who prefer a $\mathrm{V}$-shaped theory do not give much weight to this consideration. For them, the similarity of surface grammar is an oddity that masks a vast difference in semantics (see Gibbard (1980) for the classic expression of this line of argument). Accordingly, the two branches of semantical analysis go off in different directions very early on. Examples of such V-shaped theories would be those that give Lewis-Stalnaker-style analyses of counterfactuals, but explain indicatives in terms of the material conditional or in terms of conditional probabilities.

Now, where will the features that preclude the assertability of $A \rightarrow \neg A$ etc. be located in these pictures? Let us refer to pragmatic features of this kind by "P!" and to semantic features by "S!", and see where we should place them.

We have seen that the pragmatic constraints on counterfactuals do not add to a pragmatic preclusion. There will thus not be a P! on the right branch; but, given that we are, as a premise of this essay, committed to explaining the connexive intuitions one way or the other, we should therefore expect a S! somewhere on this branch.

On the other hand, we have seen that it is plausible to expect a P! on the left (indicative) branch. Nothing I have presented here should lead us to conclude that a $\mathrm{S}$ ! couldn't be on that branch, as well; in this case we would be dealing with a sort of double causation for indicatives: Statements like $A \rightarrow \neg A$ are unassertable for

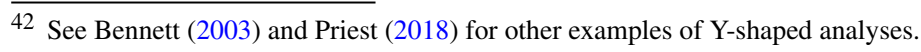


semantic and pragmatic reasons alike (presumably, the pragmatic reasons should be seen as preempted by the semantic ones).

So, two scenarios are possible, depending on whether there is a S! on the indicative branch or not. Here is how those two possibilities look like for V-shaped theories:

P! : Pragmatic feature that prohibits assertability of $A \rightarrow \neg A$ etc.

S! : Semantic feature that prohibits truth of $A \rightarrow \neg A$ etc.

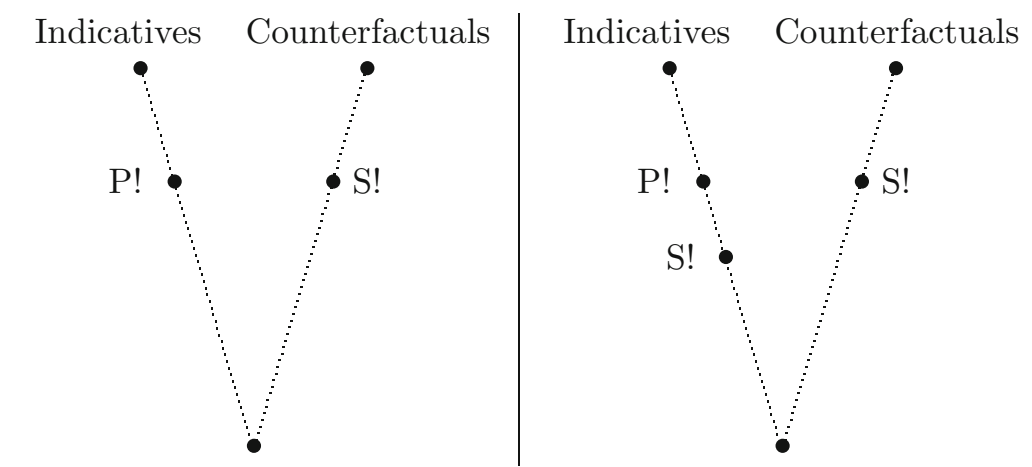

Fig. 2 Where the semantic action might be on a V

The right shape is somewhat unlikely given that convincing connexive logics are arguably scarce, but of course it is a possible pattern. As it displays a form of causal overdetermination, where pragmatics is preempted by semantics, such a shape would suggest a ready answer to Q- REVISION: No, pragmatics will not come to the rescue of those who do not want to revise logic. The semantic features that make up S! will make their influence on logic choice felt.

On the other hand, the left shape leaves the possibility of a positive answer to QREVISION open, and we will therefore keep exploring it further. This shape would be exemplified by an account that accepts, say, a Stalnaker-style explanation of counterfactuals ${ }^{43}$ but reverts to a material analysis for indicatives.

For Y-shaped explanations, (see Fig. 3), the considerations above mean that the $\mathrm{P}$ ! needs to occur after the branching point. For otherwise, we would see a pragmatic explanation of the unassertability of $A \rightarrow \neg A$ etc. for counterfactuals, which, according to my arguments in Sect. 6.2, is not to be expected.

The location of the S!, however, seems to me to be likely to be on the stem of the $\mathrm{Y}$, simply because it seems plausible to me that a difference in semantics that is great enough to warrant the unassertability of $A \rightarrow \neg A$ etc. will be so fundamental that it becomes implausible to still call the account Y-shaped, even if there has been quite a bit of material in common to the account of indicatives and counterfactuals. The picturesque way of talking about V-and Y-shaped accounts is useful, but one should keep in mind that it is only a means of illustration and should not be taken too literally.

43 Or some other account of counterfactuals that satisfies the (humbly) connexive theses. 


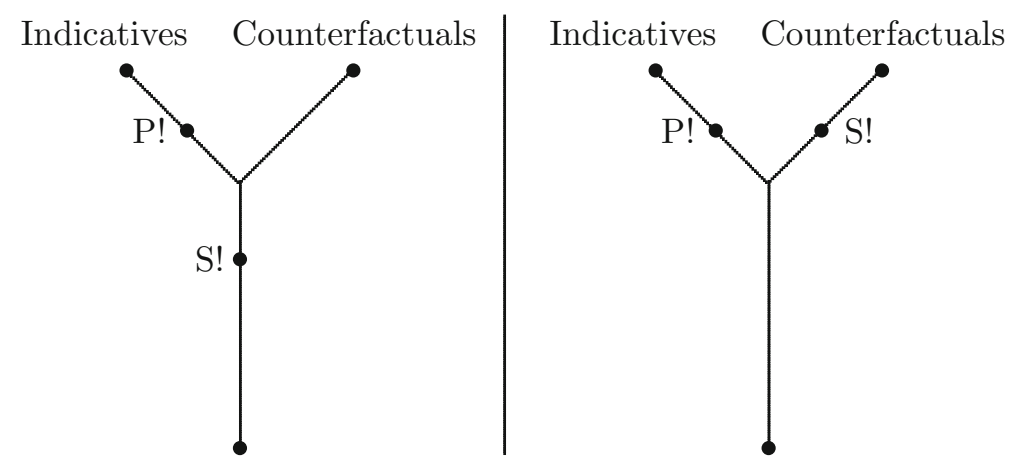

Fig. 3 Where the semantic action might lie on a Y

Whether something is a $\mathrm{Y}$ or a V is a matter of degree. Even the clearest V-shaped account will, if you zoom in, display a little stem. For example, there will not be a sensible theory that gives the meaning of indicatives by solely interpreting linguistic items while factoring facial expressions into the meaning of counterfactuals. So, a theory that starts with linguistic expressions in both cases, but goes off into wildly different directions afterwards, will still have a little common stem; the information that linguistic expressions are what is to be interpreted lives on that stem, if nothing else (and in most cases, there will be much more).

So, whether we are dealing with a Y-shaped picture or a V-shaped one is a matter of discretion, but I think it probable that it will be more natural to call a theory that has an S! on only one branch a V-shaped theory.

That leaves the class of Y-shaped accounts in a similar state as the right shape in Fig. 2. Yes, the pragmatics of indicatives would rule out statements that offend our connexive intuitions, but those have been taken out of the race at an earlier stage by semantic considerations already. The answer to Q- REVISION would, once again, be negative. To give an example for such a theoretical scenario, Stalnaker's theory simply displays a single $\mathrm{S}$ ! on the stem of the $\mathrm{Y}$ and, in fact, no $\mathrm{P}$ ! at all, as we have seen above that his pragmatic theory does not rule out statements like $A \rightarrow \neg A$. If, however, Stalnaker would be convinced to accept IP in standard contexts, he would be lead to the shape we are talking about.

In either case, how to treat statements like $A \rightarrow \neg A$ logically is a question that pragmatics has little to add to in such an environment. More generally, it seems to me that a defender of a Y-shaped account who wants to do justice to the connexive intuitions will simply have to provide a semantic theory that validates the connexive theses. A Y-shaped theory requires a connexive logic.

We have, thus, established for which class of theories a study of the pragmatics might have the most interesting logical upshots regarding connexivity. More to the point, we have determined which shape a theory must have to make a positive answer to Q- REVISION possible. To repeat, it is the shape of a theory that gives a quite distinct semantic account of indicatives and counterfactuals, and for which the unassertability of $A \rightarrow \neg A$ etc. is explained pragmatically for indicatives in standard contexts, and semantically for counterfactuals. 


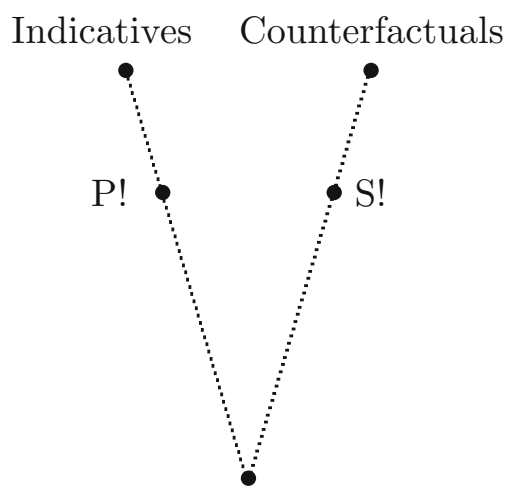

Fig. 4 Theories in which pragmatics can have an influence on logic choice

\section{Semantic Responses to Presupposition Failures}

Now, exactly what the logical upshots of a consideration of the pragmatics of indicatives might be is the topic of this section. There are three possible outcomes, corresponding to three responses to the question what happens to the truth value of an indicative conditional whose presupposition is not met.

I found that few if any of the authors who write about the pragmatics of conditionals give explicit answers to this question. However, the following three options are discussed in the more general literature on failures of presuppositions and conventional implicatures.

(A) The pragmatic failure is a conventional implicature and has no effect on the truth value of the statement.

(B) If one sees the pragmatic failure as a presupposition failure, then the first option holds that neither something true nor something false was said. ${ }^{44}$

(C) The other prominent way of treating a statement with a failed presupposition is to view it as simply false.

The debate between proponents of options (B) and (C) has been going on since Peter Strawson's classic paper On Referring (Strawson 1950), in which he made the case for option (B). A good starting point for delving into this debate is von Fintel's (2004). If any consensus at all has been achieved, then it is probably that naive intuitions will not be ultimately decisive here. They are too uncertain and context sensitive to bear that much weight. As Beaver (2001, p. 10) writes:

Judgements on whether sentences are meaningless or false are typically hazy indeed, it is hard even to know how to pose to a naive informant the question of whether a given sentence is meaningless or false - and the debate arguably never reached a satisfactory conclusion.

\footnotetext{
44 Here, I run together two things that Soames (1989) thinks important to keep apart: The first is the idea that a presupposition failure leads to the assertion of a proposition that has no truth value and thus exemplifies a truth value gap. The second is that it leads to the failure of an uttered sentence to express a proposition at all.

I do so because the relevant upshot of those two views for my discussion seems to me to be the same.
} 
The question will more likely be decided by theoretical concerns: How easy will it be to integrate either option into a larger theory of language and logic that gives a correct and, as far as possible, elegant account?

To judge this question in our case, let us see how these options would play out for statements like $A \rightarrow \neg A$, etc. Applying these general strategies to concrete examples like

If today is Monday, then today isn't Monday.

leads to judgments such as these:

(Á) According to the first option, I might be saying something true with such a statement. I might also be saying something false; this will be decided by the semantics of the conditional and the factual question which day of the week it is. (E.g., for classical logicians the statement will be judged false when uttered on Monday, and true otherwise.) In either case, the conditional will be pragmatically unassertable. Thus, this option would underwrite the intuition I have called UNASSERTABILITY (see Sect. 3).

$\left(\mathbf{B}^{\prime}\right)$ According to the second view, the statement above does not have a truth value. This accords well with pre-theoretic intuitions that find the statement bizzarre and even maybe non-sensical. Such intuitions would be expressed by UNTRUTH.

$\left(\mathbf{C}^{\prime}\right)$ Lastly, proponents of the third option would judge the assertion of such statements as simply false. This accords with intuition FALSITY.

As I have said above, I locate my own intuitions between UNTRUTH and FALSITY; but again, intuitions will probably not be what decides between those two, and maybe they aren't even reliable enough to confidently rule out mere UNASSERTABILITY.

So, let us turn to more theoretical concerns. First, for both option (B) and (C), we will need more machinery to evaluate the truth values of conditionals than we might have expected, because those truth values now depend on whether the presupposition is met, and that depends on what speakers believe to be possible. In particular, we need the semantic machinery necessary to evaluate indexicals. What we will need to evaluate "If $A$, then $B$ " is exactly what we need to determine the truth value of

I believe $A$ might be true, and, if $A$, then $B$.

Indeed, option (C) agrees with the truth value of that statement, while option (B) gives a different result if the presupposition is not met (namely, it judges "If $A$, then $B$ " truthvalueless in such a case).

There is a critique of similar cases of seemingly extreme context dependence of conditionals by Edgington (1986), who has specifically Stalnaker's view (Stalnaker 1975a) in mind here. ${ }^{45}$ He responds in Stalnaker (2011) to this worry; ${ }^{46}$ I will not go into their argument further, I only want to flag that this is a point that anyone who wants

\footnotetext{
45 See also her SEP entry on Indicative Conditionals, Edgington (2014).

46 Accounts on which indicative conditionals report subjective probability judgments have roughly similar worries to address. The general phenomenon of surprising context dependences of truth conditions has been discussed under the label "truth-conditional pragmatics", a term so apt that it serves as title to both Bezuidenhout (2002) and Recanati (2010).
} 
to implement (B) or (C) will have to address, and if that can't be done adequately, this would speak in favor of option (A).

But let us get to another theoretical concern, the one that is at the center of this whole investigation: What effect do the different options above have on logic choice?

\section{The Pragmatic Effects on the Choice of Logic}

In terms of logic choice, options (A) and (C) represent black and white responses as far as connexivity is concerned:

Proponents of option (A) will say that logic is unconstrained by pragmatic failures. Thus, even though the connexive intuitions should not be dismissed, a non-connexive logic faces no problems in accommodating them.

On the other hand, friends of option (C) will have to say that instances of $A \rightarrow \neg A$ are always false. Therefore, instances of $\neg(A \rightarrow \neg A)$ etc. will always be true, and consequently a fully connexive logic will be called for.

It is option (B) that might allow for a more nuanced answer. Again, according to (B), $A \rightarrow \neg A$ is neither true nor false. What that means for $\neg(A \rightarrow \neg A)$ depends on the semantics of negation, in particular how it reacts to truth value gaps. If negation is a truth-functional connective, there are only two plausible options, sometimes called external and internal negation, respectively:

\begin{tabular}{c|c|}
\multicolumn{2}{c}{$\neg_{e}$} \\
\hline \hline$T$ & $F$ \\
\hline$N$ & $T$ \\
\hline$F$ & $T$ \\
\hline
\end{tabular}

\begin{tabular}{c|c|}
\multicolumn{2}{c}{$\neg_{i}$} \\
\hline \hline$T$ & $F$ \\
\hline$N$ & $N$ \\
\hline$F$ & $T$ \\
\hline
\end{tabular}

Applied to our example, the first view says that

It is not the case that if today is Tuesday, it is not Tuesday.

is negating something that is not true, and thus that it itself is true.

The second view denies that, maybe because it views the statement to be so strange that it does not make any more sense than the statement that is negated, and therefore, that it is likewise not even false. This would be more in line with Strawson's original argument, but of course he was not thinking about conditionals in that context.

In any case, logically the first choice (external negation) leads to the same outcome as option (C): All four of ARISTOTLE, BOETHIUS and the two UNSAT-conditions will be required (possibly, if you agree with me, with the humble restrictions discussed in Sect. 2).

The second, internal, interpretation of negation will, in contrast, not require the validity of ARISTOTLE and BOETHIUS: A truth value gap will usually not be designated; ${ }^{47}$ therefore, $\neg(A \rightarrow \neg A)$ will not be expected to be a logical truth, since it will always take this undesignated value.

\footnotetext{
47 That said, I have written a whole book that centers around designated truth value gaps (Kapsner 2014). However, I was not thinking of presupposition failures as the primary sources of such gaps.
} 
Does that mean that someone who champions the internal interpretation is in the same boat as proponents of option (A) above, in that their view imposes no strictures on logic when it comes to connexive ideas?

Not quite: As $A \rightarrow \neg A$ will always take an undesignated value, we are reminded of the unsatisfiability clauses mentioned in section 2 . To repeat:

UnSat1: In no model, $(A \rightarrow \neg A)$ is satisfiable.

UnSat2: In no model $A \rightarrow B$ and $A \rightarrow \neg B$ are satisfiable simultaneously (for any $A$ and $B$ ).

In Estrada-González and Ramírez-Cámara (2016), discussed logics that obey UNSAT1 and UNSAT2 but do not necessarily validate ARISTOTLE and BOETHIUS, and they chose to call these logics Kapsner-strong connexive logics. However, beyond introducing the notion, neither their paper nor any other I am aware of in the connexive literature makes any suggestion as to what the possible use of such logics might be. So far, the line of thought above is the only I can think of that would motivate such logics, and it does so quite clearly in the case of UNSAT1: If we treat both $A \rightarrow \neg A$ etc. and $\neg(A \rightarrow \neg A)$ etc. as truthvalueless, we will not want to ask for the validity of ARISTOTLE, but we will want to insist on UNSAT1.

On the other hand, the story that tries to motivate UNSAT2 along parallel lines is not quite as simple. The pragmatic dissonance that we observed arose if a single speaker asserted both $A \rightarrow B$ and $A \rightarrow \neg B$. If the statements are made by different speakers, that dissonance might disappear: if you assert $A \rightarrow B$ and I assert $A \rightarrow \neg B$, then that does not show that either of us isn't taking $A$ to be an epistemic possibility. So, the presupposition might actually be met and a truth value gap might not be called for. And consequently, UNSAT2 might not be a necessary part of the account.

However, we have already at the end of Sect. 8 seen that the truth-value-gap analysis forces us to see conditionals as more indexical semantic phenomena than we might have expected. In view of that, we should maybe modify UNSAT2 in the following way:

Unsat2*: In no model, the propositions expressed by $A \rightarrow B$ and $A \rightarrow \neg B$, as uttered by the same speaker, are satisfiable simultaneously (for any $A$ and $B$ ).

I don't mean to be specific on how a model theory that incorporates speaker roles in this way might look like; as one of the reviewers rightly remarks, one example of the kind of theory this might lead to is Jaśkowski's (1999). There, the requirement would, roughly, translate to the conjunction of $A \rightarrow B$ and $A \rightarrow \neg B$ being embedded under the same modal operator.

I am not sure whether Estrada-González and Ramírez-Cámara would still want to call a logic that satisfies only UNSAT1 and UNSAT2* Kapsner-strongly connexive, or indeed, whether there might not be better phrased alternatives to this amendment. Also, the fact that my discussion seems to provide some possible motivation for a property that bears my name makes me slightly suspicious of my own subconscious motives. Therefore, I will simply speak of Unsatisfiability-logics in the short rest of this piece $^{48}$ and mean by that logics that capture the spirit of UNSAT1 and UNSAT2 with

\footnotetext{
48 I'd like to emphasize that this is for local convenience only and is not meant to introduce a new label to the larger discussion, which is already somewhat cluttered terminologically. Note also that very recently,
} 
the understanding that they might have to be adapted to the specifics of the semantic theory at hand, maybe along the lines of UNSAT $2 *$, or maybe in some other way.

It seems clear that the constraints on an Unsatisfiability-logic might be easier to fulfill than those of full connexivity, as the former constraints are a proper part of the latter, at least if connexivity is understood along the lines of my characterization in Sect. 2 and factoring in the idea of the last paragraph concerning the modification of UNSAT2. If we should find ourselves with a satisfying logic that obeys the unsatisfiability clauses, but does not achieve full connexivity, then that could be seen as the kind of theoretical clue that might help us decide whether UNTRUTH or FALSITY is the best way of making our connexive intuitions more precise.

I sum up the possibilities for indicative conditionals (on a V-shaped theory with no S! on the left branch) in the following table:

\begin{tabular}{|r|c|c|l|}
\hline $\begin{array}{r}\text { Pragmatic } \\
\text { Phenomenon }\end{array}$ & Intuition & $\begin{array}{l}\text { Semantic Effect } \\
\text { of Prag. Failure }\end{array}$ & $\begin{array}{l}\text { Constraint on } \\
\text { Logic }\end{array}$ \\
\hline \hline $\begin{array}{r}\text { Conventional } \\
\text { Implicature }\end{array}$ & Unassertability & True or False & $\begin{array}{l}\text { No Constraint } \\
\text { on Logic }\end{array}$ \\
\hline Presupposition & Untruth & $\begin{array}{c}\text { Truth Value } \\
\text { Gap }\end{array}$ & $\begin{array}{l}\text { Unsatisfiability- } \\
\text { Logic }^{a}\end{array}$ \\
\hline $\begin{array}{c}\text { Presupposition } \\
\text { Or full connexivity if an external analysis of negation is adopted. }\end{array}$ & $\begin{array}{c}\text { Falsity } \\
\text { Full Connexivity }\end{array}$ \\
\hline
\end{tabular}

As an impetus for future logical explorations, maybe most interesting in this table is the middle ground that the second line represents. As I pointed out in the first part of this essay, it is admittedly very hard to find a strongly connexive logic that has a convincing and well motivated semantics, even under the restrictions of humble connexivity; however, reaching such a point with a logic that only has to satisfy Unsat1 and Unsat $2 *$ seems much more feasible.

That said, all of the lines in the table above present interesting possibilities with their unique benefits, but also with their own challenges that any theory that tries to make them more concrete will have to deal with. What is, at the very least, commendable about all of them is that they all take the connexive intuitions seriously and try to provide a theoretical explanation of them, a task that much of mainstream philosophical logic has not come to terms with so far.

\section{Summary}

Let me end by bringing it all together: I have argued that the connexive intuitions are too strong to be ignored, and have invested some time into making them more explicit before trying to explain them (Sects. 2, 3).

an interesting modification of my notion of strong connexivity has been offered that breaks the idea up into two ways of understanding it (see Omori and Wansing 2020). Although one of the reviewers has asked me to comment on this development, I have decided to leave this for another time, as the new idea essentially involves gluts and goes beyond the perimeter drawn in footnote 10 . 
In this piece, my aim was to find out whether a pragmatic explanation of these intuitions might work. This, first, required me to delve into the pragmatics of conditionals and to synthesize an account from the discussions in the literature that strikes me as correct (Sect. 5).

The upshot of applying that account to the probelm at hand is this: I think that explaining the connexive intuitions pragmatically might be quite a viable route in the case of indicatives, but not for counterfactuals (Sect. 6).

The presupposition that does the relevant work is that the antecedent is an epistemic possibility for the speaker; that presupposition only attaches to indicatives, not to counterfactuals. ${ }^{49}$

I argued that, at least if the underlying theory of conditionals is of the V-shaped variety (see Sect. 7), the pragmatic account might allow someone to stick to their nonconnexive logic for indicatives and still acknowledge the correctness of the connexive intuitions. What that means for logic depends on how one chooses to treat pragmatic failures (Sects. 8, 9).

The upshot of all of this is presented in the following two answers to my leading questions:

Q-Pragmatic: Are there pragmatic principles that can help explain our connexive intuitions?

Answer: Yes, in the case of indicative conditonals. No, in the case of counterfactuals.

Q-Revision: In the case of indicatives: Is this pragmatic explanation all there is to it, and will it thus lead to less drastic logical revision than what the connexive logicians call for, or maybe none at all?

Answer: Possibly, if (a) our best theory of conditionals turns out to be V-shaped and (b) if presupposition failures are not taken to lead to falsehood.

The above presents the result of an inquiry I decided to engage in because I had a hazy hunch that there seemed to be a certain pragmatic dimension to my connexive intuitions. ${ }^{50}$ I could at the time not articulate it any better, because up to that point, I had never inquired what the literature had to say about the pragmatics of conditionals. I am now confident that that hunch was correct, in the manner that my answer to QPRAGMATIC indicates. The positive result (for indicatives) and the negative one (for counterfactuals) strike me as equally important.

As I said up front, when it comes to Q- REVISION I have tried to treat all of the options impartially and to point out what seems to me the most fruitful ways in which they might be further pursued and elaborated. However, it is not the case that this aspired impartiality reflects a truly agnostic stance. After thinking about this for a long while, my own general feeling, which I allow myself now to express, is that

\footnotetext{
49 The pragmatic analysis, by the way, likewise does nothing for the forms of connexivity discussed by Priest (1999) involving entailments, i.e. systems satisfying, as he puts it, $\neg(A \models \neg A)$ and $(A \rightarrow B) \models$ $\neg(A \rightarrow \neg B)$ and their variants. There is no presupposition that says that the speaker needs to assume that the premises of an argument are possibly true.

50 One reviewer reports having had a similar hunch, and speculates that it "has been lurking in the backs of many logicians' heads".
} 
a purely pragmatic explanation of the connexive intuitions is potentially useful, but unsatisfying at a deeper level.

Here is an analogy; if you find that it is a fitting one, then this will indicate that we share that same intuitive discomfort with a positive answer to Q- REVISION. Say you are interested (hopefully for purely theoretical reasons) in the problem of blackmail. Thinking hard about it, you find that it is exceedingly hard to say why blackmail is wrong and, indeed, why it should be considered a crime. Thinking even longer about it, you come up with a purely economic argument about misallocated resources that indicates that a society that makes blackmail a crime will be better able to maximize economic efficiency.

This is not a fanciful example. One can read Coase (1988) for a great exposition of the theoretical conundrum and the economic argument. Coase's argument has since engendered a sizeable commentarial literature, but let us assume, for the sake of analogical argument, that it is roughly correct. We have, then, a way forward for theoretically justifying the legal statutes concerning blackmail, statutes that help prevent deeds that are intuitively obviously wrong. Maybe we're even reasonable happy with legal theorists turning their attention to more pressing matters. But deep down, few will get the feeling that the question has been fully answered, and, moreover, that the answer came from quite the right angle. Coase himself ended his essay on blackmail by noting: "It would be a sad day if all the answers had to be provided by economists." ${ }^{51}$ In the future, we may yet get to a deeper and better understanding of the wrongness of blackmail. Maybe this will suggest better legal instruments to deal with it, and maybe this will even lead to different verdicts in a few cases.

This is, broadly, how I feel about the pragmatic explanation of connexive intuitions. Not that asserting "If $A$, then not- $A$ " is quite as bad as blackmailing someone, but I do sense close similarity in the explanatory pattern: In adopting the pragmatic explanation, we have at least not made the mistake of ignoring the problem. But there is a lingering sense that the ultimate solution will be one in which a deeper reason for these intuitions will be uncovered (in terms of the illustrations above, that the ultimate picture will be one in which a $\mathrm{P}$ ! is preempted by a $\mathrm{S}$ ! on the same branch). This will not make the pragmatic account irrelevant, just as the economical considerations of blackmail will be valuable even after a deeper moral account of blackmail's nature is found. The pragmatic failures I have pointed to in this essay are part of what is wrong with assertions that go against connexive intuitions for indicatives. A full understanding of what it wrong with such assertions will involve the pragmatic part of the story. And maybe, if my gut feeling is misguided, this is the whole story.

Acknowledgements I'd like to thank Heinrich Wansing, Hitoshi Omori, Hannes Leitgeb, Bruno Jacinto, Andrea Iacona, Nissim Francez, Brian Leahy, Christopher Badura, Dolf Rami and three anonymous referees, as well as audiences in Bochum and Munich for their insightful comments and criticism. They have greatly helped improve the material and the exposition. In part, my research has been supported by the Deutsche Forschungsgemeinschaft (DFG, German Research Foundation), Project 436508789, and project Grant PIDPID-107667GB-I00 of the Spanish Ministry of Science and Innovation.

Funding Open Access funding enabled and organized by Projekt DEAL.

51 Coase (1988, p. 676). 
Open Access This article is licensed under a Creative Commons Attribution 4.0 International License, which permits use, sharing, adaptation, distribution and reproduction in any medium or format, as long as you give appropriate credit to the original author(s) and the source, provide a link to the Creative Commons licence, and indicate if changes were made. The images or other third party material in this article are included in the article's Creative Commons licence, unless indicated otherwise in a credit line to the material. If material is not included in the article's Creative Commons licence and your intended use is not permitted by statutory regulation or exceeds the permitted use, you will need to obtain permission directly from the copyright holder. To view a copy of this licence, visit http://creativecommons.org/licenses/by/4.0/.

\section{References}

Anderson, A. R. (1951). A note on subjunctive and counterfactual conditionals. Analysis, 12(2), 35-38.

Beaver, D. I. (2001). Presupposition and assertion in dynamic semantics (Vol. 29). Stanford: CSLI Publications.

Bennett, J. (2003). A philosophical guide to conditionals. Oxford: Oxford University Press.

Bergmann, M. (1981). Presupposition and two-dimensional logic. Journal of Philosophical Logic, 10(1), $27-53$.

Bezuidenhout, A. (2002). Truth-conditional pragmatics. Philosophical perspectives, 16, 105-134.

Coase, R. H. (1988). Blackmail. University of Virginia Law Review, 74, 655-676.

Crupi, V., \& Iacona, A. (ms). The evidential conditional.

Edgington, D. (1986). Do conditionals have truth conditions? Crítica: Revista Hispanoamericana de Filosofía, 18(52), 3-39.

Edgington, D. (2014). Indicative conditionals. In E. N. Zalta (Ed.), The Stanford encyclopedia of philosophy. Metaphysics Research Lab, Stanford University, winter 2014 edition.

El-Rouayheb, K. (2009). Impossible antecedents and their consequences: Some thirteenth-century arabic discussions. History and Philosophy of Logic, 30(3), 209-225.

Estrada-González, L., \& Ramírez-Cámara, E. (2016). A comparison of connexive logics. IfCoLog Journal of Logics and Their Applications, 3(3), 341-355.

Estrada-González, L., \& Ramírez-Cámara, E. (2020). A Nelsonian response to 'the most embarrassing of all twelfth-century arguments'. History and Philosophy of Logic, 41(2), 101-113.

Gibbard, A. (1980). Two recent theories of conditionals. In W. Harper, G. Pearce, \& R. Stalnaker (Eds.), Ifs (pp. 211-247). Berlin: Springer.

Grice, H. P. (1989). Studies in the way of words. Cambridge: Harvard University Press.

Horn, L. (2007). Towards a Fregean pragmatics: Voraussetzung, Nebengedanke, Andeutung. In I. Kecskes \& L. R. Horn (Eds.), Explorations in pragmatics: Linguistic, cognitive and intercultural aspects (pp. 39-69). Berlin: de Gruyter.

Iacona, A. (2019). Strictness and connexivity. Inquiry, 1-14.

Jaśkowski, S. (1999). A propositional calculus for inconsistent deductive systems. Logic and Logical Philosophy, 7(7), 35-56.

Kapsner, A. (2012). Strong connexivity. Thought, 1(2), 141-145.

Kapsner, A. (2014). Logics and falsifications, volume 40 of trends in logic. Berlin: Springer.

Kapsner, A. (2019). Humble connexivity. Logic and Logical Philosophy, 28(3), 513-536.

Kapsner, A., \& Omori, H. (2017). Counterfactuals in Nelson logic. In A. Baltag, J. Seligman, \& T. Yamada (Eds.), International workshop on logic, rationality and interaction (pp. 497-511). Berlin: Springer.

Karttunen, L., \& Peters, S. (1979). Conventional implicature. In C. K. Oh (Ed.), Syntax and semantics. Vol. 11: Presupposition. New York: Academic Press.

Leahy, B. (2011). Presuppositions and antipresuppositions in conditionals. Semantics and Linguistic Theory, $21,257-274$.

Lenzen, W. (2019). Leibniz's laws of consistency and the philosophical foundations of connexive logic. Logic and Logical Philosophy, 28(3), 537-551.

Lenzen, W. (2020). A critical examination of the historical origins of connexive logic. History and Philosophy of Logic, 41(1), 16-35.

Lewis, D. (1979). Scorekeeping in a language game. In Semantics from different points of view (pp. 172187). Springer. 
McCall, S. (2012). A history of connexivity. In Handbook of the history of logic (Vol. 11, pp. 415-449). Elsevier.

Moss, S. (2012). On the pragmatics of counterfactuals. Noûs, 46(3), 561-586.

Omori, H., \& Wansing, H. (2020). An extension of connexive logic c. In N. Olivietti, R. Verbrugge, S. Negri, \& G. Sandu (Eds.), Advances in modal logic (Vol. 13, pp. 503-522). London: College Publications.

Pfeifer, N. (2012). Experiments on Aristotle's thesis: Towards an experimental philosophy of conditionals. The Monist, 95(2), 223-240.

Pizzi, C., \& Williamson, T. (1997). Strong Boethius' thesis and consequential implication. Journal of Philosophical Logic, 26(5), 569-588.

Potts, C. (2005). The logic of conventional implicatures. Oxford: Oxford University Press.

Potts, C. (2015). Presupposition and implicature. The Handbook of Contemporary Semantic Theory, 2, 168-202.

Priest, G. (1999). Negation as cancellation and connexive logic. Topoi, 18(2), 141-148.

Priest, G. (2008). An introduction to non-classical logic: From if to is (2nd ed.). Cambridge: Cambridge University Press.

Priest, G. (2018). Some new thoughts on conditionals. Topoi, 37(3), 369-377.

Recanati, F. (2010). Truth-conditional pragmatics. Oxford: Oxford University Press.

Soames, S. (1989). Presupposition. In Handbook of philosophical logic (pp. 553-616). Springer.

Stalnaker, R. (1975a). Indicative conditionals. Philosophia, 5(3), 269-286.

Stalnaker, R. (1975b). Presuppositions. In D.J. Hockney, W.L. Harper, \& B. Freed (Eds.), Contemporary research in philosophical logic and linguistic semantics (pp. 31-41). Springer.

Stalnaker, R. (1987). Inquiry. Cambridge: Bradford Books.

Stalnaker, R. (2002). Common ground. Linguistics and Philosophy, 25(5-6), 701-721.

Stalnaker, R. (2011). Conditional propositions and conditional assertions. In A. Egan \& B. Weatherson (Eds.), Epistemic modality (pp. 227-248). Oxford: Oxford University Press.

Strawson, P. F. (1950). On referring. Mind, 59(235), 320-344.

von Fintel, K. (2004). Would you believe it? The king of france is back! Presuppositions and truth-value intuitions. In M. Reimer \& A. Bezuidenhout (Eds.), Descriptions and beyond (pp. 315-341). Oxford: Oxford University Press.

Wansing, H. (2020). Connexive logic. In E. N. Zalta (Ed.), The Stanford encyclopedia of philosophy. Metaphysics Research Lab, Stanford University, spring 2020 edition.

Wansing, H., Omori, H., \& Ferguson, T. M. (2016). The tenacity of connexive logic: Preface to the special issue. IfCoLog Journal of Logics and their Applications, 3, 279-296.

Wansing, H., \& Unterhuber, M. (2019). Connexive conditional logic. Part I. Logic and Logical Philosophy, 28(3), 567-610.

Weiss, Y. (2019). Connexive extensions of regular conditional logic. Logic and Logical Philosophy, 28(3), 611-627.

Publisher's Note Springer Nature remains neutral with regard to jurisdictional claims in published maps and institutional affiliations. 